\title{
TU/e EmonONEN

\section{Large redshift in photoluminescence of p-doped InP nanowires induced by Fermi-level pinning}

Citation for published version (APA):

Weert, van, M. H. M., Wunnicke, O., Roest, A. L., Eijkemans, T. J., Silov, A. Y., Haverkort, J. E. M., Hooft, 't, G. W., \& Bakkers, E. P. A. M. (2006). Large redshift in photoluminescence of p-doped InP nanowires induced by Fermi-level pinning. Applied Physics Letters, 88(4), 043109-1/3. [043109]. https://doi.org/10.1063/1.2168255

DOI:

10.1063/1.2168255

Document status and date:

Published: 01/01/2006

\section{Document Version:}

Publisher's PDF, also known as Version of Record (includes final page, issue and volume numbers)

\section{Please check the document version of this publication:}

- A submitted manuscript is the version of the article upon submission and before peer-review. There can be important differences between the submitted version and the official published version of record. People interested in the research are advised to contact the author for the final version of the publication, or visit the $\mathrm{DOI}$ to the publisher's website.

- The final author version and the galley proof are versions of the publication after peer review.

- The final published version features the final layout of the paper including the volume, issue and page numbers.

Link to publication

\section{General rights}

Copyright and moral rights for the publications made accessible in the public portal are retained by the authors and/or other copyright owners and it is a condition of accessing publications that users recognise and abide by the legal requirements associated with these rights.

- Users may download and print one copy of any publication from the public portal for the purpose of private study or research.

- You may not further distribute the material or use it for any profit-making activity or commercial gain

- You may freely distribute the URL identifying the publication in the public portal.

If the publication is distributed under the terms of Article 25fa of the Dutch Copyright Act, indicated by the "Taverne" license above, please follow below link for the End User Agreement:

www.tue.nl/taverne

Take down policy

If you believe that this document breaches copyright please contact us at:

openaccess@tue.nl

providing details and we will investigate your claim. 


\title{
Large redshift in photoluminescence of $p$-doped InP nanowires induced by Fermi-level pinning
}

\author{
M. H. M. van Weert, O. Wunnicke, and A. L. Roest \\ Philips Research Laboratories, Professor Holstlaan 4, he5656 AA Eindhoven, The Netherlands
}

T. J. Eijkemans, A. Yu Silov, and J. E. M. Haverkort

COBRA Inter-University Research Institute, Eindhoven University of Technology, Department of Applied

Physics, P.O. Box 513, 5600 MB Eindhoven, The Netherlands

G. W. 't Hooft and E. P. A. M. Bakkers ${ }^{\text {a) }}$

Phillips Research Laboratories, Professor Holstlaan 4, 5656 AA Eindhoven, The Netherlands

(Received 31 August 2005; accepted 1 December 2005; published online 26 January 2006)

\begin{abstract}
We have studied the effect of impurity doping on the optical properties of indium phosphide (InP) nanowires. Photoluminescence measurements have been performed on individual nanowires at low temperatures $(5-70 \mathrm{~K})$ and at low excitation intensities $\left(0.5-10 \mathrm{~W} / \mathrm{cm}^{2}\right)$. We show that the observed redshift $(200 \mathrm{meV})$ and the linewidth $(70 \mathrm{meV})$ of the emission of $p$-type InP wires are a result of a built-in electric field in the nanowires. This bandbending is induced by Fermi-level pinning at the nanowire surface. Upon increasing the excitation intensity, the typical emission from these $p$-InP wires blueshifts with $70 \mathrm{meV} /$ decade, due to a reduction of the bandbending induced by an increase in the carrier concentration. For intrinsic and $n$-type nanowires, we found several impurity-related emission lines. () 2006 American Institute of Physics. [DOI: 10.1063/1.2168255]
\end{abstract}

Nanowires (NWs) have recently attracted much interest, due to the tunability of their optical and electronic properties. Several types of NW-based devices have been fabricated, including logic gates, ${ }^{1}$ single-electron transistors (SET), ${ }^{2}$ superconductive devices, ${ }^{3}$ light-emitting diodes, ${ }^{4}$ and lasers. ${ }^{5}$ This recent progress, in combination with the ability to integrate III-V semiconducting NWs monolithically into silicon, makes them very promising elements for future technologies. ${ }^{6,7}$ However, in order to fabricate complementary-metal-oxide-semiconductor-like NW devices, one must be able to control impurity doping to obtain both $n$-type and $p$-type NWs. There are some reports on the doping of $\mathrm{ZnO},{ }^{8} \mathrm{Si}$ and $\mathrm{Ge},{ }^{9,10} \mathrm{GaAs},{ }^{11}$ and InP (Ref. 4) NWs. The effect of the incorporation of impurities has been demonstrated in electrical field-effect devices ${ }^{8-10}$ or by the observation of diode behavior. ${ }^{4}$ Although photoluminescence (PL) has proven to be a sensitive technique for examining impurity doping of semiconductors, it has so far not been used for NWs.

Here, we report on low-temperature PL experiments on single InP NWs with different doping types. We show that the incorporation of impurities greatly affects the emission spectra of the NWs.

The NWs in this study have been synthesized by the vapor-liquid-solid growth mechanism. The vapor phase was established by laser ablation of a powdered $\operatorname{InP}(>6 \mathrm{~N})$ target. First, a $2 \AA$ thin gold film is evaporated on $\mathrm{SiO}_{2}$ that breaks up into small islands at elevated temperatures. The NWs grow from the gold particles and have a typical diameter of $50 \mathrm{~nm}$. In order to introduce dopants into the NWs, either elemental Se or $\mathrm{Zn}_{3} \mathrm{P}_{2}$ powder was incorporated in the target at a concentration of $1.0 \times 10^{-3}$ and $1.0 \mathrm{~mol} \%$, respectively. From these NWs, field-effect transistor devices were fabricated that showed that the Se-doped NWs were effec-

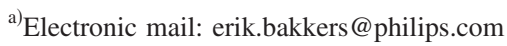

tively $n$-type, ${ }^{2}$ and the Zn-doped NWs were $p$-type. ${ }^{12}$ Devices based on nominally undoped (intrinsic) InP NWs were typically low conducting at zero gate voltage, but turned on at positive gate voltages, exhibiting a large on / off ratio of $10^{7}$. Although the NWs show luminescence at room temperature, the measurements have been performed at low temperature $(5-70 \mathrm{~K})$ in order to be able to use excitation intensities below $10 \mathrm{~W} / \mathrm{cm}^{2}$. The samples were excited with a continuous HeNe laser $(632.8 \mathrm{~nm}, 10 \mu \mathrm{W})$ in a nonconfocal Zeiss laser scan microscope. The PL signal was collected by the same objective lens and was focused onto a spectrophotometer with a nitrogen-cooled InGaAs array detector. The integration time was $60 \mathrm{~s}$ per spectrum. PL spectra of $i$-InP and $n$-InP were recorded from more than ten NWs from different batches, while five $p$-InP NWs have been characterized. The excitation intensity was varied from 0.5 to $10 \mathrm{~W} / \mathrm{cm}^{2}$.

In Fig. 1, representative low-temperature $(15 \mathrm{~K})$ emission spectra of intrinsic, $n$-type and $p$-type InP NWs are shown. The emission spectra of the intrinsic NWs show three distinct lines as indicated in Fig. 1(a). The emission line (1) at $1.41 \mathrm{eV}$ is around $7 \mathrm{meV}$ below the band-gap energy of bulk InP at $15 \mathrm{~K}$ (1.42 eV) (Ref. 13), and could be due to an excitonic or a donor-related emission. If it is of excitonic origin, the peak is lower in intensity than expected, which might be due to the large surface-to-volume ratio. When we, however, compare it to emission from $n$-type NWs, it seems more likely that it is a donor-to-valence band (DV) transition. We attribute the main luminescence line (2) at $1.377 \mathrm{eV}$ to a conduction band-to-acceptor (CA) recombination with carbon acting as the acceptor $\left(E_{A}=40 \mathrm{meV}\right) .{ }^{13}$ The emission line (3) at $E=1.33 \mathrm{eV}$ might be assigned to a phonon replica of the CA-pair recombination (2) or to a deep acceptor level.

The $n$-type InP NWs exhibit two emission peaks. We assign the main emission line (1) at $E=1.414 \mathrm{eV}$ to a DV transition; the ionization energy for Se in InP is $5 \mathrm{meV} .{ }^{13} \mathrm{The}$ emission line (2) at $1.383 \mathrm{eV}$ is assigned to a CA transition ${ }^{14}$ due to carbon impurities. The peak positions of the various 


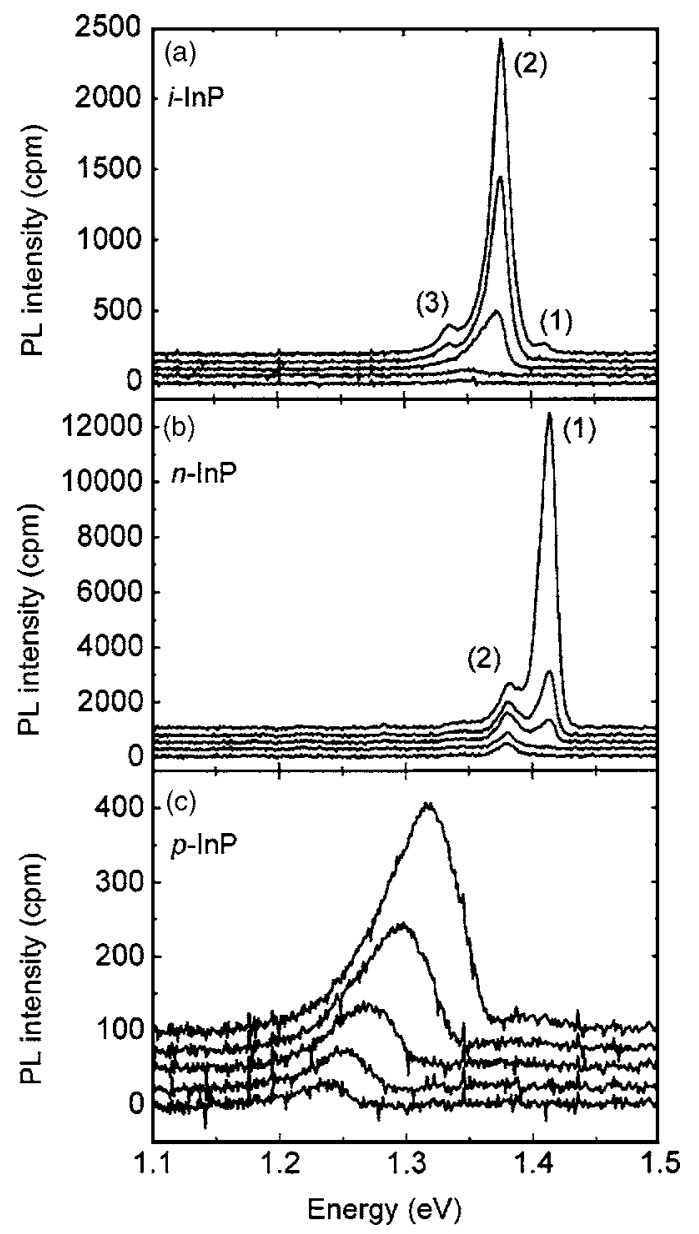

FIG. 1. PL spectra in counts per minute versus energy (eV) of an (a) intrinsic, (b) $n$-type, and (c) $p$-type InP NW, measured at $15 \mathrm{~K}$. The different lines represent, from bottom to top, excitation intensities of $0.5,1.0,2.0,5.0$, and $10 \mathrm{~W} / \mathrm{cm}^{2}$, respectively. The spectra have been shifted vertically for clarity.

emissions do not change upon varying the excitation intensity. Furthermore, the linewidths, defined as the full width at half maximum (FWHM), of the peaks are typically $20 \mathrm{meV}$ in the temperature range of 5-70 $\mathrm{K}$ and do not depend on the excitation intensity. Such relatively large linewidths in NW spectra are attributed to inhomogeneous surface charges. ${ }^{15,16}$

A representative result of the measurements on $p$-InP NWs is shown in Fig. 1(c). We want to point out two important differences in comparison with $i$-InP and $n$-InP NWs. The first difference is the linewidth of the emission, which is in the range of 70-100 meV (FWHM) for the NWs studied. This is more than three times larger than the FWHM in intrinsic and $n$-type NWs. The most remarkable observation is however the large illumination-induced blueshift of the PL peak: The peak energy shifts from $1.23 \mathrm{eV}$ to $1.31 \mathrm{eV}$ upon a factor of 20 increase of excitation intensity in contrast to the constant peak positions observed in intrinsic and $n$-type NWs. Since the peak shifts gradually toward higher energy rather than in steps and no separate peaks are observed, we believe that the spectra taken at different excitation intensities show one and the same band, originating from a single transition. One possible explanation for such a shift would be a Coulomb shift occurring for a DA pair transition. ${ }^{17}$ However, we find a peak shift of $70 \mathrm{meV} /$ decade, which is more than two times higher than values reported previously for $p$-InP of $10-35 \mathrm{meV} /$ decade. $^{17}$ Therefore, we believe that the emission shift has a different origin. the emission shift has a different origin.
Downloaded 13 Sep 2007 to 131.155 .108 .71 . Redistribution subject to AlP license or copyright, see http://apl.aip.org/apl/copyright.jsp

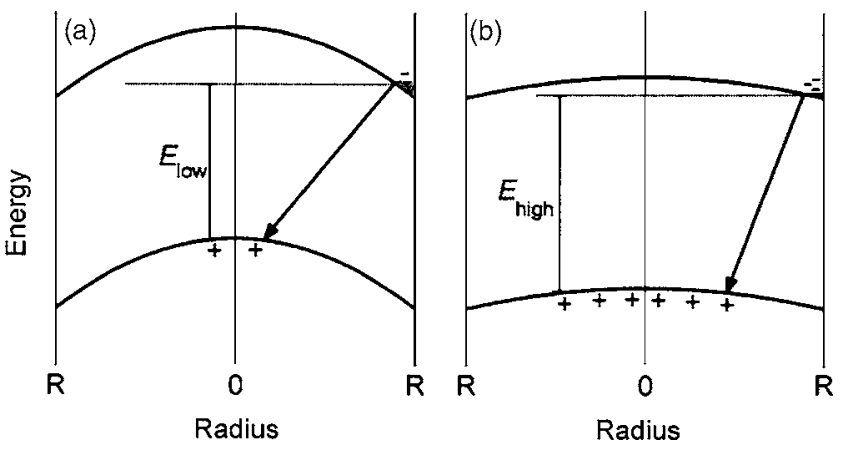

FIG. 2. The effect of bandbending on the luminescence. With low excitation intensity (a), the created charge carriers are separated in space, resulting in a low quantum efficiency. With a higher excitation intensity (b), the photoexcited charge carriers reduce the bandbending, resulting in a higher PL energy as well as an enhanced quantum efficiency.

We propose that the shift is due to bandbending [Fig. 2(a)]. It is known for bulk $p$-InP that an oxide layer at the surface pins the Fermi level. ${ }^{18}$ Holes in $p$-doped material will then diffuse toward the surface and subsequently be trapped at the donorlike surface states, causing strong bandbending with a negatively charged surface depletion region. The band bending is particularly large for $p$-InP, since the Fermi level is expected to be pinned at only around $0.1 \mathrm{eV}$ below the conduction band. Such surface-induced depletion has been observed by means of photoconductivity for $\mathrm{GaN}$ nanowires. ${ }^{19}$ It is not seen in $i$-InP NWs, where the number of impurities is much lower, insufficient for the creation of a charged depletion region.

Upon excitation, charge carriers are created, which will be separated in space by the built-in electric field. Electrons will get confined at the surface of the NW, while the holes accumulate at the center of the NW, neutralizing the ionized acceptor states, as illustrated in Fig. 2(a). The accumulation of the photoexcited charge carriers will continue until a dynamic equilibrium has been reached. An electron near the surface recombines with a hole in the center, giving a transition energy of $E_{\text {low }}$ [Fig. 2(a)]. The separation in space will result in a low transition probability, due to small overlap of wave functions of electrons and holes. When the excitation intensity is increased [Fig. 2(b)], more charge carriers will be generated, diminishing the bandbending. As a result, the emission energy increases to $E_{\text {high }}$ and the transition probability is enhanced, since the separation in space has decreased.

Figure 3 shows PL spectra of a second $p$-InP NW on a semilogarithmic scale. Remarkably, the offset and the slope of the spectrum at the low-energy side remains the same for different excitation intensities and temperatures. This interesting phenomenon may be explained by considering diffusion of charge carriers in the longitudinal $(z)$ direction of the NW. The excitation decreases the bandbending locally, which in turn will result in a local potential maximum for holes. As a result, the photoinduced charge carriers will drift along the $z$ direction toward regions where the bandbending is less affected by excitation and the potential for the holes is lower. Recombination in those regions, near the edges of the spot, will continue to produce emission at $E_{\text {low }}$. Hence, the PL spectra of $p$-InP NWs represent an integral of emission from various regions ranging from the edge of the spot, where the bandbending has not changed [Fig. 2(a)], to the 


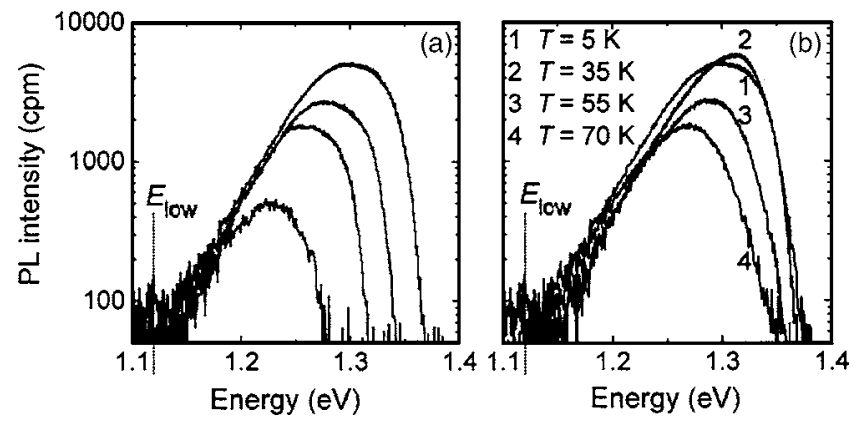

FIG. 3. PL spectra of a $p$-type InP NW for different excitation intensities (a) and temperatures (b), plotted on a semilogarithmic scale. Measurements were performed at $T=5 \mathrm{~K}$. The different spectra in (a) represent excitation intensities of $1.0,2.0,5.0$, and $10 \mathrm{~W} / \mathrm{cm}^{2}$, from bottom to top. The temperatures in (b) are as indicated in the figure.

by excitation [Fig. 2(b)]. Remarkably, the slope at the highenergy side is not affected by the excitation intensity [Fig. 3(a)], whereas it decreases with increasing temperatures [Fig. 3 (b)]. We suggest that the temperature affects the diffusion of photoexcited carriers. If we assume that the diffusion length of carriers exceeds the radius of the excitation spot $(3 \mu \mathrm{m})$, an increase in the temperature will broaden the carrier distribution in the $z$ direction. This broadening results in a lower maximum intensity accompanied with a redshift, consistent with the experimental observations.

In conclusion, intrinsic, $n$-type, and $p$-type InP NWs have distinctly different optical properties, as shown here by PL measurements. Intrinsic NWs show a dominant acceptorrelated emission and $n$-type NWs show a dominant donorrelated emission. As for $p$-InP, the PL spectra show a large redshift and a broadened peak. This peak exhibits a large dependence on the excitation intensity with a strong blueshift of $70 \mathrm{meV} /$ decade. We explain this behavior by strong bandbending due to Fermi-level pinning at the surface. Our ob- servations might have important implications for the design of optoelectronic devices based on NWs.

${ }^{1}$ Y. Huang, X. Duan, Y. Cui, L. J. Lauhon, K. H. Kim, and C. M. Lieber, Science 294, 1313 (2001).

${ }^{2}$ S. De Franceschi, J. A. van Dam, E. P. A. M. Bakkers, L. F. Feiner, L. Gurevich, and L. P. Kouwenhoven, Appl. Phys. Lett. 83, 344 (2003).

${ }^{3}$ Y. J. Doh, J. A. van Dam, A. L. Roest, E. P. A. M. Bakkers, L. P. Kouwenhoven, and S. De Franceschi, Science 309, 272 (2005).

${ }^{4}$ M. S. Gudiksen, L. J. Lauhon, J. Wang, D. C. Smith, and C. M. Lieber, Nature (London) 415, 617 (2002).

${ }^{5}$ M. H. Huang, S. Mao, H. Feick, H. Yan, Y. Wu, H, Kind, E. Weber, R. Russo, and P. Yang, Science 292, 1897 (2001).

${ }^{6}$ E. P. A. M. Bakkers, J. A. van Dam, S. de Franceschi, L. P. Kouwenhoven, M. Kaiser, M. Verheijen, H. Wondergem, and P. van der Sluis, Nat. Mater. 3, 769 (2004).

${ }^{7}$ T. Mårtensson, C. P. T. Svensson, B. A. Wacaser, M. W. Larsson, W. Seifert, K. Deppert, A. Gustafsson, L. R. Wallenberg, and L. Samuelson, Nano Lett. 4, 1987 (2004).

${ }^{8}$ H. T. Ng, J. Han, T. Yamada, P. Nguyen, Y. P. Chen, and M. Meyyappan, Nano Lett. 4, 1247 (2004).

${ }^{9}$ Y. Cui and C. M. Lieber, Science 291, 891 (2001).

${ }^{10}$ D. Wang, Q. Wang, A. Javey, R. Tu, H. Dai, H. Kim, P. C. McIntyre, T. Krishnamohan, and S. K. C, Appl. Phys. Lett. 83, 2432 (2003).

${ }^{11}$ K. Hiruma, M. Yazawa, T. Katsuyama, K. Ogawa, K. Haraguchi, M. Koguchi, and H. Kakibayashi, J. Appl. Phys. 77, 447 (1995).

${ }^{12}$ X. Duan, Y. Huang, Y. Cui, J. Wang, and C. M. Lieber, Nature (London) 409, 66 (2001).

${ }^{13}$ Properties, Processing and Applications of Indium Phosphide, edited by T. Pearsall (INSPEC, 2000).

${ }^{14}$ Since we do not observe a Coulomb shift, the peak is unlikely to be related to a donor-to-acceptor (DA) transition. In addition, due to the quasi onedimensionality of the NWs, the DA transition probability is reduced, compared to bulk systems with similar dopant concentrations.

${ }^{15}$ M. S. Gudiksen, J. W. Wang, and C. M. Lieber, J. Phys. Chem. B 106, 4036 (2002).

${ }^{16}$ L. K. van Vugt, S. J. Veen, E. P. A. M. Bakkers, A. L. Roest, and D. A. M. Vanmaekelbergh, J. Am. Chem. Soc. 127, 12357 (2005).

${ }^{17}$ R. M. Sieg, B. Chatterjee, and S. A. Ringel, Appl. Phys. Lett. 66, 3108 (1995).

${ }^{18}$ W. E. Spicer, I. Lindau, P. Pianetta, P. W. Chye, and C. M. Garner, Thin Solid Films 56, 1 (1979).

${ }^{19}$ R. Calarco, M. Marso, T. Richter, A. I. Aykanat, R. Meijers, A. v. d. Hart, T. Stoica, and H. Lüth, Nano Lett. 5, 981 (2005). 